brazilianpoliticalsciencereview

ART I CLE

\title{
On The Limits of Free Speech: Towards the Fair Value of
}

\section{Communicative Liberties*}

\author{
Renato Francisquini \\ Postdoctoral Researcher, Universidade Federal de Minas Gerais, Brazil
}

This study addresses, from a theoretically oriented perspective, the relationship between freedom of expression and democracy, trying to assess its implications for the regulation of mass media. Starting with a legal case in which a TV channel and a journalist were prosecuted for hate speech, looking at the reaction of the São Paulo Press Association to the case, I examine three perspectives on the statute and the reach of expressive libertiesthe Millian Principle, the collectivist approach, and the participatory view-which connect these liberties to the ideas of moral autonomy and self-determination. For different, but related, reasons, these views present a conception of free speech that would not garner universal agreement in a pluralistic society. Moreover, some of the ideas defended could justify rules (or the absence of them) that might harm the social bases of self-respect. In opposition to these lines of thought, I argue for the fair value of communicative liberties; i.e., the idea that everyone should have access to the same rights and effective conditions to exercise communication. This means a fair distribution of opportunities for occupying the mediated public space and the establishment of rules to discourage the dissemination of ideas that fail to acknowledge the equal respect that we owe to each other as members of the political association. Democracy, I shall contend, comprises both private and public autonomy. A fair system of communicative freedom is to be seen as the outcome of and the upholding force in a democratic society.

Keywords: Freedom of expression; mass media; communicative equality; self-government; autonomy. 
To try to deny the citizen this freedom [of the pen], means withholding from the ruler all the knowledge of those matters which, if he knew about them, he would himself rectify, so that he is thereby put in a self-stultifying position. (Immanuel Kant - "On The Common Saying - This may be true in Theory, but it Does Not Apply in Practice". In: Kant Political Writings).

Tring $\mathrm{n}$ an unprecedented decision, the Brazilian Court has convicted a broadcast corporation and one of its most important journalists for hate speech. Bandeirantes TV, one of the four big media corporations in the country, presents a daily show in which reporters follow the police while they chase and arrest supposed criminals. José Luiz Datena, the host of the program, is responsible for analyzing and commenting on the images. Both Datena and the corporation were convicted over a show aired in July 2010 in which Datena, in a sort of a Dostoievskian argument, claimed the supposed criminal must be an atheist. According to Datena, "Atheists have no limits; that is why we see crimes like these. Atheists kill and commit other atrocities. They think they are their own God". After a protest by the Brazilian Atheist Association (ATEA), the Brazilian Court sentenced Bandeirantes TV and Datena, compelling them to air a two-hour show discussing freedom of consciousness and religious diversity. In the case of noncompliance, they would have to pay five thousand dollars in fines each day until the program was made.

The São Paulo Press Association reacted by publishing a note opposing the conviction, in which it stated, "one cannot think of democracy in Brazil without fighting for the rights enshrined in the United Nations' Charter of Human Rights, which protects the human right to freedom of expression and therefore the right to communication"1. The note continued, "When a journalist or a TV station is prevented from the right to free speech, we disrespect democracy and the rule of law. This is not a discussion about freedom of consciousness or religious diversity; more important is the question of freedom of expression and the essential and legitimate right of communicatio"2. According to the Association, it would be failing

\footnotetext{
${ }^{1}$ Emphasis added.

2 Emphasis added.
} 
to protect its principles if it did not oppose the conviction publicly: "We couldn't go without a retaliation note because the constitutional defense of one of the most important principles of natural law, that is the right to freedom of expression, is comparable to a defense of life and of the natural freedom of human beings"3.

Therefore, the São Paulo Press Association maintains that a Court infringes on human rights whenever it condemns journalists and broadcasters for their activities. It conceives free speech as being derived from natural law; hence, it is a right that requires no further justification. Such a controversy raises a debate regarding the statute and the character of freedom of expression in societies in which public communication is more and more dependent upon the mediation exercised by technology. This discussion surrounds the relationship between free speech and media freedom ${ }^{4}$, and concerns the question of who the legitimate holder of rights to freedom of expression is or should be, as well as what the limits of these rights are in terms of different communicative practices. It is based around the idea of the priority of liberty and its interactions with other values. From a theoretical perspective, an important debate exists around the concept of free speech and its place within a broader, more general, idea of freedom. From a practical perspective, the discussion is related to different forms of legitimate regulation and their impact upon the guarantee of values such as autonomy.

I

Departing from the aforementioned case, this paper will address the normative issue of freedom of expression within the landscape of democratic societies in which the mediated form of communication appears as a central feature. From a certain perspective, the development of IT technologies and the spread of democratic practices have made it easier than ever to establish communication both widely and effectively. Yet, some theoretically accepted concepts and legally enforced norms tend to restrict, rather than support, democratic communication. Here I refer to views such as the one espoused by the São Paulo Press Association.

\footnotetext{
3 Emphasis added.

${ }^{4}$ I shall use "press freedom" or "media freedom" to refer to the same principle.
} 
Opposing that line of thought, I will argue that moral autonomy is not achieved through the negative liberty to impart ideas, because the private autonomy to express oneself implies the public autonomy to be treated as equal by the basic structure of society. I sustain, from a liberal-egalitarian perspective, that the freedom to communicate is justified primarily by the axiom of human fundamental equality 5 and, second, by the concept of democratic communication, which is the result and the instrument of such an ideal ${ }^{6}$. This perspective, I shall argue, puts the regulation of free speech at the forefront of the debate regarding both the fair distribution of communicative opportunities and the laws that could potentially be applied to the content of discourses.

In what follows, I intend to discuss the implications of such a perspective, as well as what justifies a movement away from the dominant view of free speech. To begin with, I present three different perspectives on the principle of freedom of expression and its implications for media regulation. First, I will consider the "Millian" argument, which is based on the idea that freedom of expression is justified by the requirements of a certain conception of individual autonomy. A second perspective, which I shall call the "collectivist approach", argues that only those expressions that contribute to democratic deliberation by self-governing citizens should be protected. The third view justifies the Constitutional protection of certain speech acts, based on the expressive interest of the speakers in participating in the process of self-determination. My argument is that, all in all, these perspectives fail to provide adequate justification for freedom of expression. I shall then defend the concept of the fair value of communicative liberties; i.e., the idea that everyone should have access to the same rights and the adequate conditions to express themselves and to be heard in the process of public opinion and democratic will formation.

5 Or the idea according to which people should enjoy equal liberty to follow their conception of the good life. According to such a view, decisions should be considered collective and citizens would be considered fully equal if, and only if, the social arrangements engendered reasons for the binding decisions that could be accepted by everyone as reasonable.

${ }^{6}$ According to Iris Young, "Democracy is a process of communication among citizens and public officials, where they make proposals and criticize one another, and aim to persuade one another of the best solution to collective problems" (2010, p. 52). 
II

Freedom of expression is commonly associated with the search for truth, the right to individual self-expression, the proper functioning of democracy, and finally, the balance between stability and social change. It is not only necessary for citizens to exercise their moral capacities to have a sense of justice and to defend a conception of the good. The right to free speech appears as an alternative to revolution and to the use of force, both of which greatly threaten basic liberties: "we should underrate their importance [of a free press] if we thought they just guaranteed liberty; they maintain civilization" (TOCQUEVILLE, 2004, p. 518). Moreover, an epistemic value is often assigned to the guarantee of freedom of expression; that is, better or more democratic decisions are associated with the free circulation of antagonistic and diverse opinions.

Scanlon (2003b) argues that a strong doctrine of free speech holds that some speech acts must be immune from interference, despite the harm that they could cause and that would be sufficient to prohibit non-expressive acts. To defend such a position, it is necessary to present arguments that justify the privileges associated with speech acts. In general, the arguments offered are consequentialist: some acts must be protected because this would generate better outcomes than would be the case if they were subjected to restriction. Alternatively, however, one can rest the case upon rights or another non-consequentialist principle, such as the idea of natural law mobilized by the São Paulo Press Association. Following John Stuart Mill's On Liberty, Scanlon (2003b) argues that the act of self-expression is generally self-regarding ("self-affecting") and that it should be limited only if it is likely to cause harm to others. In this sense, Scanlon (2003b) suggests that justifications for restricting free speech acts should not be sustained on the argument that free speech, if left unrestricted, would lead people to form false beliefs or to consider performing actions that could be harmful. Based on the Kantian idea of a legitimate government ${ }^{7}$, Scanlon states that:

There are certain harms which, although they would not occur but for certain acts of expression, nonetheless cannot be taken as part of a justification for legal restrictions on these acts.

7 According to Kant (1991), a legitimate government is one whose authority is acknowledged by the citizens and is considered free, equal, autonomous, and rational. 
These harms are: (a) harms to certain individuals which consist in their coming to have false beliefs as a result of those acts of expression; (b) harmful consequences of acts performed as a result of those acts of expression, where the connection between the acts of expression and the subsequent harmful acts consists merely in the fact that the act of expression led the agents to believe (or increased their tendency to believe) these acts to be worth performing (SCANLON, 2003b, p. 14).

The advantage of this principle, according to Scanlon (2003b), is that it applies to any kind of speech act; it is not determined by the superiority of certain kinds of right (e.g., political rights) or by the value of expressions that belong to a particular domain (e.g., artistic expression, scientific discussion, etc). In other words, it specifies the special nature of acts of expression, as well as the basic distinction between these and other forms of action, without referring to their content. To the extent that the notion of autonomy that underlies this principle is quite weak ${ }^{8}$, the author wants to argue that this is an "exceptionless" restriction upon governmental authority. The Millian Principle, therefore, imposes a limitation upon the reasons that one can use as a justification for government interference in individuals' freedom. Thus, it should not be considered an individual right.

At first glance, Scanlon (2003b) assumes that freedom of expression is a good that we intuitively rank as more important than, for instance, the maintenance of absolute peace or rock-bottom taxes. However, the argument has a limited reach as its boundaries are defined by considerations external to the idea of freedom of expression itself:

Access to means of expression for whatever purposes one may have in mind is a good which can be fairly or unfairly distributed among the members of a society, and many cases which strike us as violations of freedom of expression are in fact instances of distributive injustice. This would be true of a case where, in an economically inegalitarian society, access to the principal means of expression was controlled by the government and auctioned off by it to the highest bidders, as is essentially the case with broadcasting licenses in the United States today (SCANLON, 2003b, p. 22).

${ }^{8}$ According to Scanlon (2003b), much weaker than the Kantian conception. 
By placing the case for fair communicative opportunities outside the domain of free speech and ranking the right to individual self-expression as more important than other considerations, Scanlon subjects the exercising of political liberties to a variation of the Kantian conception of individual autonomy. His argument is committed to the protection of this principle, understood as the capacity one has to see oneself as being "sovereign in deciding what to believe and in weighing competing reasons for action" (SCANLON, 2003b, p. 15). According to this view, society disrespects individual autonomy by regulating speech, even when the outcomes would normally justify the restriction of other acts to prevent harmful consequences ${ }^{9}$. Autonomy, according to Scanlon's interpretation, is a given feature that is assigned to all individuals.

Let us consider, however, a person who is socialized in an environment where public discourse tends to depict those of her class, race, sex, etc as mere instruments for others' ends, always in subordinate positions. In this same society, news and entertainment shows, movies and songs constantly present scenes of violence that involve people with one or more specific characteristics (related to an ethnicity, a sexual preference, or a religion, perhaps), as if these characteristics naturally lead people to behave in harmful ways. Would such a person be in a position to consider herself as being equal to other members of that society? Would she see herself and those who share the same characteristics as being selfgoverning individuals, acting accordingly?

It is impossible not to take into account the "sour grapes" phenomenon. In other words, self-determination is affected not only by a person's own choices; it is also the outcome of a belief system that tells someone what the available options are (BRISON, 1998). The Millian Principle gives no consideration whatsoever to the social pathologies that can be generated by public communication and are organized in accordance with the idea of attributed autonomy. If it does not consider the circumstances capable of undermining the opportunities citizens have to express themselves, the principle does not protect citizens' right to equal selfrespect.

9 Later, Scanlon himself recognized that "the Millian Principle [...] placed too tight a constraint on possible justifications for restricting expression" (2003a, p. 02). 
If we acknowledge the importance of the communicative environment in the formation of public opinions, especially of those expressions that are intended to reach a broad audience through the means of communication, we can see that the Millian Principle provides an account that is too limited to promote a system of free speech in which personal autonomy can be enjoyed equally by everyone. The social basis of self-respect, which is fundamental in the exercising of our moral capacities, "includes a person's sense of his own value, his secure conviction that his conception of his good, his plan of life is worth carrying out. And second, selfrespect implies confidence in one's ability, so far as it is within one's power, to fulfill one's intentions" (RAWLS, 2003, p. 386). In failing to protect the social bases of self-respect, the Millian Principle is not able to organize the basic structure of society in a way that provides each citizen with fair opportunities to participate in collective self-determination (RAWLS, 2003, pp. 155-156).

\section{III}

A different perspective on the association between autonomy and free speech is presented by the North American philosopher Alexander Meiklejohn. His "collectivist" account rests on the idea, similar to the one implicit in the Millian Principle, that the privileged status of certain speech acts is justified by their relation to citizens' ability to self-govern. In one of his most quoted sentences, Meiklejohn argues that "What is essential is not that everyone shall speak, but that everything worth saying shall be said" (1948, p. 26). The purpose of the Constitutional devices applied to expressive freedom is to protect the community from the mutilation of its "thinking process"; it is not a model of unregulated talkativeness, but of a group of free and equal individuals cooperating in a collective enterprise, in which they mobilize responsible and regulated arguments.

Autonomous decisions, in this sense, are a product of the listener's opportunities to receive information and opinions from different sources. The selfgoverning enterprise cannot be effective unless each citizen has adequate and fair chances to discover and her preferences and decisions. In some ways, this is an anti-elitist argument, since it denies that only a few virtuous and wise citizens have 
the competence to make appropriate or "good" binding decisions ${ }^{10}$. A system that gives people opportunity to speak but does not offer the necessary tools to think will be full of empty speech and reckless voting (GASTIL, 2008). On the other hand, however, this raises the possibility that the collective power of society might be able to function to decide when enough information is available on the issues being debated.

Meiklejohn (1948) believes that the roots of a strong guarantee of free speech can be found in the American Constitutional design of popular sovereignty. The fact that popular sovereignty requires a free and open discussion among citizens goes against justifications for government interference in political deliberation. In this line of thought, government regulation would violate citizens' right to participate in collective self-determination. The restrictions would be unfair because they would undermine the quality of the debate and its reflexivity. Meiklejohn's argument is distilled in the following paragraph:

Shall we, then, as practitioners of freedom, listen to ideas which, being opposed to our own, might destroy confidence in our form of government? Shall we give a hearing to those who hate and despise freedom, to those who, if they had the power, would destroy our institutions? Certainly yes! Our actions must be guided, not by their principles, but by ours. We listen not because they desire to speak, but because we need to hear. If there are arguments against our theory of government, our policies in war or in peace, we the citizens, the rulers, must hear and consider them for ourselves. That is the way of public safety. It is the program of self-government (MEIKLEJOHN, 1948, p. 56-57).

Nevertheless, Meiklejohn (1948) does not claim that all discourses should be constitutionally protected. Although he rules out regulations based on the points of view conveyed in a discourse, here, such a privilege extends only to those speeches that convey what "shall be said". In other words, we must consider the

10 Meiklejohn's (1948) argument was a riposte to Justice Holmes' "doctrine of clear and present danger". Justice Holmes argued that U.S. Congress was allowed to prohibit speeches where the content could potentially harm society. This rule, put into practice in 1919, was considered by Meiklejohn as a restriction upon-and not just an interpretation of-the First Amendment to the American Constitution. Furthermore, and most importantly, the exclusion of certain arguments from the public space would make deliberation less pluralistic, preventing the audience from being properly informed of all the views relevant to their judgment. This is quite the same idea espoused by Dahl in relation to enlightened understanding (cf. DAHL, 2006). 
function performed by an expression in society's thinking process to decide whether it deserves the highest level of protection or not. The collective power of society is allowed to interfere in free speech through the right process if the discourse to which the restrictions apply has a private nature or does not represent a relevant contribution to public discourse. It is an account of democracy as a system in which society's thinking process occupies a prominent role in guaranteeing legitimacy. Public discourse must be regulated to assure that citizens have the chance to receive the amount and range of information adequate for making good decisions.

In a strategy similar to the one applied by Scanlon (2003b), Meiklejohn (1948) establishes some criteria to distinguish protected from unprotected speeches. Meiklejohn (1948) divides expressive liberties into two categories: the first one, "public", is assured by Constitutional devices; the second, "private", is open to public scrutiny under the right decision process. Absolute protection is guaranteed for the former category; for the latter, a limited protection is available, which is subordinate to what represents the public interest, defined by democratic deliberation, at some point in time. The distinction is justified by the double role we perform as free and equal individuals. When performing our role as selfgoverning individuals, we think, speak, and act oriented towards the general good; thus, the discourse is public and must be protected. On the other hand, in our role as governed citizens, we are allowed to legitimately pursue our personal interests and this speech is private, not requiring special barriers against the majority decision. So, the level of protection an expression deserves is ultimately related to the author's intentions in relation to its performance. If our aim corresponds with what we, as a cooperative, self-governing body, desire, then the protection is absolute; on the contrary, if we are merely defending a private interest, the freedom is limited (MEIKLEJOHN, 1948, pp. 94-95).

There are three main points that structure this approach: (1) the value of the discourse relates to its potential to enrich political public discussion, (2) a speech contributes to democratic decision-making by transmitting information that can help self-governing citizens to make wise decisions, and (3) informed choices depend on access to all the relevant points of view (MEIKLEJOHN, 1948, pp. 26-27). While the approach precludes restrictions based on the ideas that an 
expression conveys, it opens up space for rules that are applied to the agenda and procedures within public debate to guarantee the quality of political deliberation.

From this perspective, the state can work to restrict or to guarantee freedom of expression, even when it deals with distributive issues. For instance, in determined contexts, the operation of private actors who control the means by which ideas come into public sphere can restrict free speech. In such situations, the state must play an affirmative role to ensure that citizens receive all the important information required to base their decisions. Government abstention in such cases may lead to a "silencing effect" in at least two senses: first, it could harm the equal opportunities for determined citizens to communicate, since it would attach an image of inferiority to certain forms of expression; second, given that no idea becomes widely available without help from some form of publishing, a lack of access to the media can lead to the exclusion of some ideas that are important to the quality of democratic decision-making (FISS, 1996).

Sunstein, a "neo-collectivist" (SILVA, 2009), argues that the most basic and nuclear aim of the system of free speech is to assure that public communication concerning issues related to the political association is both wide and rich. Among the necessary conditions for the accomplishment of such a form of communication are the plurality of information and points of view, a norm of political equality that rules out illegitimate power, the absence of strategic manipulation of discussion, and a general orientation towards the seeking of consensus (in opposition to the mere pursue of self-interest) (SUNSTEIN, 1995, pp. 19-20). Contrary to the autonomist version presented in the former section, an innate capacity to take fully autonomous decisions is not attributed to individuals in this perspective. Given the possibility for inadequate conditions in the formation of preferences and opinions, it seems less accurate to see paternalism in the promotion of a more diversified and richer political discussion: "existing preferences should be subjected to general public discussion, rather than taken as the inevitable building-blocks for government outcomes" (SUNSTEIN, 1995, p. 20).

Such a thesis leads us to a further development of the collectivist theory described by Meiklejohn (1948): in the neo-collectivist approach, a democratic system is based on public communication that is, at once, defined and limited by its commitment to political equality. In the public sphere, then, each and every 
argument should initially be assigned the same value. All contributions to public debate would thus be assessed using the same criterion: the quality of their arguments. The influence that they gain ultimately depends exclusively on the persuasiveness of the ideas that are publicly exposed (SUNSTEIN, 1995).

Consistent with the distinction between private and public discourses, Sunstein (1995) indicates that certain forms of expression may be restricted by democratic decisions when they are seen as potentially harming a group of individuals. That would be the case in relation to types of pornography that involve violence against women, for instance. Pornography should be regulated if society decides, under the right procedures, that it harms the equality of some of its members ${ }^{11}$. As long as the restrictions are publicly sustained in terms of the quality of public deliberation and are associated with offering equal protection, thus enabling participation in collective self-government, such specific regulations should be considered legitimate, even when directed at the content of a speech act. According to Sunstein,

...the problem of pornography does not stem from offense, from public access to sexual explicit materials, from an unregulated erotic life, or from violation of traditional values or community standards. Instead, the problem consists of tangible real-world harms, produced by the portrayal of women and children as objects for the control and use of others, most prominently through sexual violence. On this view, the goal of regulation is not to stop 'offense' or to protect current social values, but to recognize and counteract sexual practices that are a vehicle for sex discrimination. Materials that eroticize rape and other forms of violence should be treated as part of sex discrimination (SUNSTEIN, 1995, p. 213).

Since such forms of communication do not represent a significant contribution to public discourse and are situated, therefore, on the periphery of the "Madisionan system", they lie outside the area deemed worthy of Constitutional protection. According to Sunstein, "under any sensible system of free expression,

11 Sunstein does not uphold criminal proscription of producers and creators of offensive material. The idea is to offer a civil resource to those offended by pornography and that are able to prove the harms caused. It would be case, for instance, of women who are objects of some kind of abuse during the production of pornographic material (SUNSTEIN, 1995, pp. 214-215). 
speech that lies at the periphery of constitutional concern may be regulated on the basis of a lesser showing of harm than speech that lies at the core" (1995, p. 215). Thus, a consequentialist argument takes place, allowing us to balance the costs and benefits of restricting an expression. This opens up space for more restrictive regulation that, all in all, is said to cause less harm than the available alternatives. With regard to pornography, there is a general belief that the sexual and reproductive status quo is permeated by arbitrary inequality toward women, which restricts the necessary conditions for the exercising of female selfdetermination. These arguments therefore justify the adoption of a regulatory regime that constrains certain expressive liberties in relation to pornographers, even though this is considered a form of private speech, in terms of the definition above (SUNSTEIN, 1995, pp. 219-222).

Hence, although the collectivist and the neo-collectivist approaches exclude regulations based on the ideas expressed in a speech act, they do it only insofar as an idea could be seen as contributing to the society's thinking process. In not protecting speeches that could be seen as promoting private interests- e.g., artistic expression- the collectivist approach distinguishes between political and non-political liberties arbitrarily, assigning less importance to the latter (COHEN, 1998).

When providing arguments for the distinction between public and private discourse, the collectivist theory returns to a justification based on the view that private speech is unnecessary-or, at least, secondary-to self-determination. In some cases, it considers that private speech promotes a trend toward individualism: a value that is pernicious in relation to democratic deliberation. Private interest is not placed under the blanket of basic liberties, which allows for legitimate regulation. Both the listener's interest in expressing their views and the association's interests in adding such opinions to the set of values that participate in the construction of collective and personal identities are relegated to second place here.

Moreover, although the theory refers to the value of free speech and the effects that it has on the audience, public and private discourses are a function of the speaker's intentions, not of the potential effects on the listeners. This perspective thus implicitly imposes a comprehensive conception of what must be 
valued by society and its individuals upon the distinction between discourses that should and should not be protected. It refuses constitutional protection for private speech, based on the normative idea that the self-interested motivation of the speaker disqualifies his/her expression from being a relevant contribution to the democratic formation of opinions and wills. According to Redish and Mollen (2009), "a speaker who refuses to believe in the value of community and instead seeks solely to further his own personal interests through expression is to be constitutionally shunned" (2009, pp. 1318-1319).

The reasons that can be considered relevant to public deliberation come in many different forms, making it hard to distinguish between valid and invalid discourses in rhetorical terms. Chambers (2012) asserts that deliberation can be enriched by personal experiences and storytelling. Artistic expression that can be classified as l'art pour l'art and thus not directly (or maybe not even indirectly) contributing to political public deliberation may be as valid to individual selfdetermination as any form of engaged art is to collective self-determination-and, moreover, the former and the latter are imbricated in a relation of mutual presupposition. Different understandings about what counts as input to public discourse can sometimes be tracked back to distinct cultural backgrounds. Moral autonomy requires that the area in which individuals exercise self-determination must be broadened as far as the limits of reciprocity. According to Post,

If the state excludes communicative contributions on the grounds of a specific sense of what is good or valuable, the states then stands in contradiction to the central project of collective self-determination. It displaces that project for the sake of heteronomously imposed norms. The internal logic of selfgovernment thus implies that with regard to the censorship of speech the state must act as though the meaning of collective identity were perpetually indeterminate within the medium of public discourse, where the debate as to what is legitimate and what is illegitimate must necessarily remain "without any guarantor and without any end" (POST, 1995, p. 1116).

In isolating the decision about what should be said and the objectives of an expression from democratic procedure, the collectivist view needs to appeal to some form of management through which it could decide whether "everything worth saying" has been said. Following the model of the town meeting, it 
establishes an a priori agreement about the goal(s) that should drive public deliberation, or suggests that a legitimate moderator should be responsible for orchestrating public discussion.

Post's (1995) objection lies in the idea that public discourse presupposes that all beliefs, all goals, and all conceptions about the role of the state are opened up to public scrutiny, as is the agenda of the discussion. According to him, what shall or shall not to be said, what is a valid argument or is not, are also subject to dispute. No particular comprehensive conception about the role of certain types of speech could be used to justify such restrictions; appeals to ideas of equality or diversity refer to particular notions of the common good that are not necessarily shared by all.

In this sense, the collectivist perspective fails to acknowledge that the value of individual autonomy is inseparable from the aspiration of selfgovernment. The protection of autonomy and the guarantee of the rights and conditions for self-government are distinct features of a just society; indeed, there is a strong connection between the two: there can be no collective self-government without personal autonomy. The communicative process deserves special constitutional protection because it is the process through which the democratic "self" is constituted: by the reconciliation between public and private autonomy.

The idea that the state must promote and organize public debate rests upon the assumption that it is capable of counterbalancing market logic and encouraging forms of autonomous thinking through mechanisms of public resource allocation. If my interpretation is correct, this conception makes extreme moral requirements of the state apparatus, which, potentially, it is not capable of accomplishing. In handing the management of the structure of public communication to the state, we leave at its discretion the possibility of resigning resource allocation to the demands of political power. To give the state the prerogative to determine the distribution of access to the means of expression is to fail to consider that the adequate operation of a system of freedom of expression would become dependent on a number of very risky factors. For the state to accomplish what is expected by the collectivist approach, functioning mechanisms to control state action must be in place. A process of selecting representatives that itself is not marked by structural inequalities and, of course, a political system that 
is open to the communicative flow that emerges from civil society must also exist (FRANCISQUINI, 2014). Following an argument made by Foucault, it can be stated that control structures come to life and threaten the autonomy even of those who create them: "If we create structures of heteronomy, we shall all, sooner or later, be condemned to inhabit them. We shall become the subjects of a power not our own" (POST, 1995, p. 1129).

IV

Based on the criticisms leveled at the collectivist approach, Post (1995) develops a different interpretation of freedom of expression that, nevertheless, also has collective self-determination as its basic underlying idea. Deviating from the former account, however, Post interprets democracy as a value rather than as a procedure. The legitimacy of a political order, argues the author, is due to the citizens' belief in the government's responsiveness to their interests and to a view of the state as being shaped by their self-determination. His key aim, therefore, is to examine how citizens could feel included in this process of collective selfgovernment and to consider how a government could be made accountable for, and responsive to, the public opinion that emerges from democratic deliberation.

Post (1995) reasons that, given certain conditions, such a public discourse enterprise can create the consensus necessary for citizens to view society as a selfgoverning body. In other words, when free from arbitrary interference, public discussion is able to produce agreement and, as a result, to contribute to the promotion of democratic legitimacy. What matters the most, therefore, is that citizens have the space to engage freely in discursive interactions with each other in the public realm ${ }^{12}$. As there cannot be a fusion between individual and collective will (à la Rousseau), citizens may only "embrace the government as rightfully 'their own' because of their engagement in these communicative processes" (POST, 1995, p. 1115). Free speech, in this sense, is also related internally to the safeguarding of public debate; nevertheless, in contrast with the collectivist approach, this requirement is to be understood as excluding regulations that restrict speakers' expressive liberties and their legitimate interests in participating in self-

12 Tied to this requirement is the obligation to subordinate the democratic will of the political system to the public opinion generated in the public sphere. 
determination processes as free and autonomous citizens. In this model, there is no argument capable of justifying the restriction of speech acts based upon the ideas they convey, whether they are private or public, or even if they are harmful to other individuals or groups.

Self-government thus depends, ultimately, on the distinction between autonomy and heteronomy. Following the traditional jurisprudence of the U.S. First Amendment, any form of interference in public discourse might be understood as potentially excluding some citizens and ideas from the medium of selfdetermination ${ }^{13}$. The communicative processes that give rise to collective will should allow both citizens and the society to reconstruct their own identities and their orientations in the moral space continuously. For this reason, public discourse should not be organized to accomplish any specific function or purpose; instead, it ought to serve as a medium through which diverse conceptions of "the good life" can collide and meet freely.

Individual and collective identities are elaborated and built within such processes, and different philosophies of life and cultural background should, and will, engender different assessments of the public discourse. This is what, in the end, gives rise to self-determination in a pluralistic society. What follows from this assumption is that communicative processes must not be managed in any sense because this would contradict the very nature of their democratic purposes:

Traditional First Amendment jurisprudence uses the ideal of autonomy to insulate the process of collective selfdetermination from such preemption. The protection of autonomy prevents the state from violating the central democratic aspiration to create a communicative structure dedicated to the 'mutual respect of autonomous will' (POST, 1995, p. 1122).

Indeed, it is the protection offered by Constitutional devices such as the First Amendment that will assure that the public discourse will be entirely open for citizens' input, thus offering citizens the necessary sense of inclusion in the process of self-government. Such principles are seen as a guarantee of the pervasive

13 Recently, this interpretation has even been used to rule out limits on the financial contributions that corporations are allowed to make to political campaigns. See Dworkin (2010). 
indeterminacy of public discourse, giving space for the support, criticism, rejection, and replacement of comprehensive notions of the common good ${ }^{14}$.

Citizens' opinions and attitudes cannot be understood as the effects of external causes or as instruments for the achievement of exogenous goals. Otherwise, public discourse would be useless to the project of self-determination, since collective identities would have been determined beforehand and from outside the multi-logical processes. Self-determining frameworks must situate individuals within "webs of hermeneutic interactions" (POST, 1995, p. 1131), understanding them as being autonomous and capable of self-government ${ }^{15}$. Autonomy, therefore, works as a "moral ascription" of the commitment to selfgovernance.

As we can see, this perspective values participation, understood as individual self-expression, and personal or collective inputs into the political system as the most important interests to be protected by the polity. This would guarantee that each particular interest is given equal special protection. The interest of speakers in imparting information and opinions has a privileged status among the rights necessary for self-determination. In this sense, it should not be subordinated to external values and interests, such as those highlighted by Meiklejohn (1948) and Sunstein (1995) -the interest in imparting information is, after all, an integral part of the morality of democracy. Since democracy is a value and not a mere procedure, the safeguards for communicative inputs should be placed at a superior level in comparison with other values. Autonomy, in what Post denominates "traditional First Amendment jurisprudence", implies a sphere free from interference of any kind, in which individuals can exercise their expressive liberties.

This participatory theory has the advantage of rejecting managerial control over free speech and public discourse. Moreover, it protects some forms of expression that would not be guaranteed Constitutional protection under the system of freedom of expression developed by the collectivist approach. There is a

\footnotetext{
${ }^{14}$ Here, conceptions of inequality or difference in status may also acquire legitimacy under the same order.

${ }^{15}$ A notion of autonomy such as the one prescribed by the collectivist approach attaches this ideal to the requirements of education and the amelioration of social conditions. This implies that it has to be achieved instead of being ascribed.
} 
strong notion of individual moral autonomy underlying this project; one that assumes as a primordial principle that individuals are the best judges, whatever the situation, of the perspectives to which they are exposed. The point Post (1995) is trying to make is not that all regulation should be ruled out; rather, he rejects rules based on comprehensive conceptions of the good life that are enforced over private actors by the collectivity.

This is a very clear and powerful idea, which cannot be dismissed without some further consideration. I would like to argue, nevertheless, that by rejecting public interference in the communicative structure that sustains self-expression, the participatory theory seems to suggest that a supposed absence of collective regulation is the most adequate system through which to sustain autonomous selfdetermination (SILVA, 2009). We must inquire whether this really is a case of leaving it down to the wild and chaotic forms of communication that are promoted by an unregulated marketplace of ideas. From another perspective, the supposed absence of control is, in any given context, a regulation by private actors with no concern whatsoever about the establishment of a system of free speech that offers citizens the chance to engage fairly in public communication. The opportunities that people have to participate in the elaboration of a democratic "self", as Post (1995) puts it, can be harmed by an unfair distribution of access to the means of expression and by speech acts that undermine people's sense of their own value. These are both examples of disrespect to citizens' right to fairly participate in the self-determination enterprise.

Communication should be valued, among other reasons, because the audience participates just as much as the speakers in the formation of public opinion, having the same rights to engage in collective self-determination. Therefore, the opportunities that audiences enjoy to participate in public discourse must be taken into account when regulating the basic structure of society. Selfgovernment is a collective project and cannot be realized without assuring fair opportunities for input into the communicative processes through which decisions gain legitimacy. According to Redish and Mollen, "just as the speaker may benefit by contributing to public discourse, so too may listeners' moral and intellectual horizons be expanded by the receipt of information and opinion" (2009, p. 1337). If a speaker has a right to self-expression but lacks the capacity to reach his/her 
intended audience, will she feel that she is a participant within collective selfgovernment to the same extent as other individuals who regularly occupy the mediated public space? On the other hand, what happens when a speaker's right to self-expression (supposing she has also the capacity to reach her audience) is used to disseminate ideas that undermine the opportunities of some members of the community to participate in self-government?

To protect certain notions of autonomy and self-determination, this approach refers to a principle of tolerance that, if followed blindly, denies some individuals and groups a rightful place in society. In recognizing this, I am not stating that there should be previous censorship or any undemocratic formula to avoid the expression of intolerant views through the means of communication. Rather, I am arguing for the establishment of rules to discourage the publication or the airing of views that disrespect characteristics and symbols that are at the core of some individual or group identities-especially when such groups exist within the less advantaged sectors of society ${ }^{16}$. Individuals are "situated selves", who have identities that are formed within the groups to which they belong and that are influenced by their interactions with other individuals. In this sense, speech and communication must be viewed as participating in the construction of our identities: "certain speech acts should be condemned because of the way they compromise the integrity of an individual's or a group's identity" (SANDEL, 1998, pp. 264-265). As such, these speech acts should be considered independently from the speaker's interest in promoting the views conveyed. As Cohen argues, when the state does not prevent private actors from restricting others' equal right to expressive liberties, it fails to protect freedom of expression and, therefore, the right to self-determination (1993, pp. 216-219). Self-respect is sustained, in part, through one's sense of oneself as an equal member of a society, who is capable of sharing the rights and duties associated with political issues and decisions. The possession of the moral sense of being able to form and exercise a conception of

16 Recently (January $7^{\text {th }}$ 2015), the journalists of the French satirical newspaper, Charlie Hebdo, were killed by Muslim radicals due to a series of cartoons that pictured the Prophet Mohammed in many disrespectful situations. The event led to much discussion about the statute and the reach of freedom of expression (the debate did not seek to justify the murders, but to question the types of material published in the newspaper). 
justice is fundamental to equality. To show respect for one another is to acknowledge and protect everyone's right to the public use of reason. It is not enough to recognize one another in some way and to give each other some rights, regardless of their content; rather, we have to recognize one another as equals "with respect to making the final authoritative judgments about collective affairs" (COHEN, 2003, p. 109). In this case, the questions of fairness and equality within the opportunities that exist to exercise communicative liberties must be taken into account.

Access to the means of publishing and/or broadcasting is equivalent to the right to express oneself, which calls for a discussion about how to distribute media outputs appropriately. The "marketplace of ideas" is a misleading metaphor when it suggests that our media system is nothing but a reflection of society (GUTMANN and THOMPSON, 1996, p. 125). Under the current conditions, in most of our established Occidental democracies, communicative liberties are allocated very much on the basis of private willingness to pay (in the financial sense). It is important to recognize that the regulation of communicative opportunities should not simply be met with a laissez faire approach. However, when it comes to the structure of the mass media in most democratic countries today, it can be said that "although viewers and listeners do not pay cash to broadcasters, each station takes account of the revenue likely to be generated by different programs, and the revenue is in large part a function of the existing audience 'demand' for programming" (SUNSTEIN, 1995, p. 58).

Having said that, in the next section, I intend to discuss a system of freedom of expression that takes into account two differing, though related, values; namely: (1) the ideal of equal respect and tolerance, which is fundamental to the reproduction of a just society- one that guarantees each of its members a fair chance to follow different and, indeed, irreconcilable conceptions of "the good life", and (2) fairness in the distribution of opportunities to participate in public discourse, from which equal access to means of communication cannot be excluded. 
V

Although there is an apparent consensus regarding the existence of a relationship between free speech, media freedom, and self-determination, the reasons mentioned so far demonstrate that there is a lack of agreement about the requirements for promoting such values. In what follows, I will to discuss why an adequate account of freedom of expression must assure the fair value of communicative liberties-i.e., citizens should have equal rights and effective opportunities, substantively speaking, to express themselves, and to have their views taken into account in the democratic process of opinion- and will formation. The implications of such an understanding for the norms that regulate free speech and the structure of public communication will also be addressed.

First of all, I take for granted that any democratic society must protect freedom of expression. However, it should also be stressed that this assumption should not be understood as merely ruling out censorship; indeed, democracy also requires that individuals have some effective means for bringing their views before the public (SCANLON, 2003c, p. 189). In a deliberative conception of democracy, the collective character of a decision refers to the fact that it emerges from an institutional arrangement that establishes the appropriate conditions for free public reasoning among equals. According to this view, citizens treat each other as equals not by giving equal consideration to each other's interests, but by offering reasons for collective decisions that could be considered legitimate by all citizens. Public discourse is, therefore, the key element in the political justification of the deliberative account of democracy that informs the argument made here.

Deliberative democracy [...] is not simply about ensuring a public culture of reasoned discussion on political affairs, nor simply about fostering the bare conjunction of such a culture with conventional democratic institutions of voting, parties, elections. The idea instead is manifestly to tie the exercise of power to conditions of public reasoning (COHEN, 1998, p. 185-186).

In contrast with the views presented in II to IV above, I want to suggest that expressive liberties should not be justified solely by their relationship to autonomy, their contribution to political deliberation, or the speaker's expressive interests. Rather, they must refer to the mutual respect that we owe to each other 
as members of the political society. Here, the regulation of society's basic structure and the opportunities that citizens have to access public space must be based on arguments that could not reasonably be rejected by any of those who are affected by the collective decisions. Although the idea of a reasonable discussion oriented towards an agreement is fundamental to the deliberative view, it does not follow that freedom of expression should be related only to those speeches intended and/or received as contributions to public discourse or oriented toward the public good. The requirement of shared reasons for the exercise of political power is what represents the full and equal membership of all in the sovereign body responsible for authorizing the exercise of that power (COHEN, 1998, pp. 213-22). To ensure that citizens are treated as equals in the argumentative process, the basic structure of the society must: (1) promote free public reasoning by offering favorable conditions for expression, participation, and association, and (2) tie the exercise of the coercive power of society to such public discussion by building an institutional framework that favors the responsiveness and the accountability of political power.

According to Habermas's discourse principle, "just those norms deserve to be valid that could meet with the approval of those potentially affected, insofar as the latter participate in the rational discourse" (HABERMAS, 1998, p. 127, emphasis added). Hence, citizens must be guaranteed favorable conditions for the exercise of self-expression that is required for self-government "in a way that provides each person with equal chances to exercise the communicative freedom" (HABERMAS, 1998, p. 128). To enlarge the opportunities that citizens enjoy for engaging in public communication, it is necessary that the principles that underlie its regulation do not become weakened but, rather, that fair conditions for expression preserved. If we consider that all citizens should be assigned fair opportunities to exercise their political liberties, we can assume that it is necessary to reduce the asymmetries in their possibilities for communicating. According to Rawls, one important condition for assuring the fair and equal value of political liberties is a guarantee of the social bases of self-respect:

The basis for self-respect in a just society is not [...] one's income share but the publicly affirmed distribution of fundamental rights and liberties. And this distribution being equal, everyone has a similar and secure status when they meet to 
conduct the common affairs of the wider society. No one is inclined to look beyond the constitutional affirmation of equality for further political ways of securing his status (RAWLS, 1999, p. 82).

Thus, by affirming these equal basic liberties, citizens of a just society publicly express their respect for one another as free and equal, "as well as their recognition of the worth all citizens attach to their way of life" (RAWLS, 1996, p. 319). If we are willing to assure the fair value of communicative liberties, it is also important to consider those forms of expression that threaten the ideal of equal opportunities. To discourage speeches that undermine the principle of autonomy, we must provide "not reasonably rejectable" reasons for regulation. One way of doing so would be to assume that certain forms of hate speech, pornography, etc function to deny some individuals the equal opportunities to express themselves and to have their opinions taken into account in relation to decisions about the future of their society.

To build a fair system of freedom of expression, the basic structure of society must be regulated to avoid extreme inequalities in access to public communication. This means upholding a more egalitarian distribution of the means to enter the public space. Press or media freedom cannot be justified through an analogy with individual freedom of expression, as in the note published by the São Paulo Press Association, or seen as a natural right that does not require justification. This type of freedom is not innocuous in any way, since it can (and it does) harm marginalized and less powerful citizens. In addition, we must bear in mind that the structure of media systems determines the access citizens that have to communicative liberties. Rules regarding the fair distribution of opportunities to establish communication, to influence the political agenda and, more broadly, to affect society's understanding of itself are important features of democratic decision-making. Preventing media oligopolies from forming and promoting different, public forms for the operation of media outlets can be effective methods to encourage fair opportunities for the exercise of communicative liberties.

The concept of guaranteeing the fair value of communicative liberties aims to ensure that each citizen has equal access to mediated public fora. "Communicative liberties" encompass expressions that are traditionally recognized 
as reasons in political deliberation and, simultaneously, those that are usually understood as external to political public deliberation. Both are central to the conception of deliberative democracy that I elaborate in this paper. The heart of citizenship, suggests Habermas (1998), is composed of both political and human rights, so that public autonomy is not restricted by moral rights and, simultaneously, the individual's private autonomy is not instrumentalized for the purposes of popular sovereignty.

\section{Toward a fair value for communicative liberties}

Having rejected the conceptions exposed from II to IV above, I have sought, in the last section, to establish the foundations for a different conceptualization of the principle of freedom of expression. My argument relates free speech to a requirement for equal respect and consideration for all members of the political association. Understanding that the exercising of political authority is legitimate only insofar as it can be publicly justified, I suggest that institutional responses to the structural conditions of the system that mediates public communication must be sustained via interpretations of the principle of freedom of expression, which can be considered a legitimate reason for public regulation by all those affected.

According to the ideal of deliberative democracy that this article espouses, the practice of self-determination includes a guarantee of both private and public autonomy. In this sense, freedom of expression requires fair access to opportunities to express oneself and to be heard in the process of opinion- and will formation, which is not necessarily associated directly with political deliberation. Such an assumption includes not only a better distribution of the chances that citizens are offered to impart information and opinions, it also encompasses forms for discouraging the expression of views that violate the ideal of equal respect. Here, acknowledging that the social bases of self-respect determine, as well as the rights and opportunities associated with free speech, the reach of political liberties.

The note published by the São Paulo Press Association fails to recognize the impact of communication-and, especially, of the mediated form of communication-upon the ways in which society depicts itself and upon the roles that both individuals and groups perform in the political association. Media systems provide "the informational building blocks to structure views of the 
world" (FEINTUCK, 1999, pp. 04-05), thus determining the avenues that many citizens have for receiving information from different sources and participating communicatively in the decisions that will strongly affect their lives. The structure of media systems functions actively to define the criteria for inclusion and exclusion of the themes and perspectives that will become apparent in the public sphere. Along with professional standards and the ethos of journalism, this structure frames the content of citizens' input into society's thinking processes.

In this study, I have suggested that much of the contemporary practice regarding freedom of expression is sustained via the idea exposed in the aforementioned media note. Such a conception of free speech is seen as a corollary of a very broad, almost unconditional, media freedom. In equalizing media freedom with individual freedom of expression, the São Paulo Press Association lacks careful consideration of how these institutions influence the exercising of both private and public self-determination, as well as other processes of political agency. If my interpretation is correct, the fair value of political liberties implies a fair distribution of communicative liberties as a necessary condition for the guarantee of democracy thus understood.

An adequate system of free expression would regulate the basic structure of society in a way that guarantees the fair value of communicative liberties: i.e., the idea that everyone is entitled to enjoy the same rights and effective conditions to participate in public discourse. When regulated according to this principle, the basic structure of society can sustain decentered, plural, and complex conversations taking place in multiple arenas, thus giving rise to a considered public opinion that informs and frames the content of democratic will. When such a system works well, it can preserve an environment of tolerance, despite the existence of pluralized and contradictory moral and ethical beliefs. In this way, public debates are able to function as multiple mirrors that are directed toward society, establishing the range of legitimate decisions that are able to inform interinstitutional dialogues and decision-making processes (FRANCISQUINI, 2014).

Revised by Cabo Verde Submitted in September 2013 Accepted in January 2015 


\section{References}

BRISON, Susan (1998), The Autonomy Defense of Free Speech. Ethics. Vol. 108, № 02, (January), pp. 312-339.

CHAMBERS, Simone (2012), Deliberation and Mass Democracy. In: PARKINSON, John and MANSBRIDGE, Jane (eds.). Deliberative Systems: deliberative democracy at the large scale. Cambridge: Cambridge University Press, pp. 5271.

COHEN, Joshua (1993), Freedom of Expression. Philosophy and Public Affairs. Vol. 22, № 03 (Summer).

COHEN, Joshua (1998), Democracy and Liberty. In: ELSTER, Jon (ed.). Deliberative Democracy. Cambridge: Cambridge University Press.

COHEN, Joshua (2003), For a Democratic Society. In: FREEMAN, S. (ed.). Cambridge Companion to John Rawls. Cambridge: Cambridge University Press.

DAHL, Robert (2006), On Political Equality. New Haven: Yale University Press.

DWORKIN, Ronald (2010), The Decision That Threaten Democracy. The New York Review of Books. Available at http://www.nybooks.com/articles/archives/2010/may/13/decisionthreatens-democracy/. Access in November 14, 2010.

FEINTUCK, Mike (1999), Media Regulation, Public Interest and the Law. Edinburgh: The Edinburgh University Press.

FISS, Owen (1996), The Irony of Free Speech. Cambridge: Harvard University Press.

FRANCISQUINI, Renato (2014), Democracia, Liberdade de Expressão e o Valor Equitativo das Liberdades Políticas. PhD Dissertation, Political Science Department, University of São Paulo.

GASTIL, J. (2008), Political Communication and Deliberation. Thousand Oaks: Sage Publications Inc.

GUTMANN, A. and THOMPSON, D. (1996), Democracy and disagreement. Cambridge: Belknap Press/Harvard University Press.

HABERMAS, Jürgen (1998), Between Facts and Norms: Contributions to a Discourse Theory of Law and Democracy. Cambridge: MIT Press.

KANT, I. (1991), Kant Political Writings. Cambdridge: Cambridge University Press.

MEIKLEJOHN, Alexander (1948), Free Speech and Its Relation to Self-Government. Available at http://digital.library.wisc.edu/1711.dl/UW.MeikFreeSp. Access in November 27, 2012. 
POST, Robert C. (1995), Meiklejohn's Mistake: Individual Autonomy and the Reform of Public Discourse. In: POST, Robert C. (1995) Constitutional Domains Democracy, Community, Management. London: Harvard University Press.

RAWLS, John (1996), Political Liberalism. New York: Columbia University Press.

RAWLS, John (1999), A Theory of Justice (revised edition). Cambridge: Harvard University Press.

RAWLS, John (2003), Justice as Fairness: a restatement. Cambridge: Harvard University Press.

REDISH, Martin H. and MOLLEN, Abby M. (2009), Understanding Post's and Meiklejohn's Mistakes: the central role of adversary democracy in the theory of freedom of expression. Northwestern University Law Review. Vol. 103, № 03.

SANDEL, Michael (1998), Democracy's Discontent: America in Search of a Public Philosophy. Cambridge: Belknap Press/Harvard University Press.

SCANLON, T. M. (2003a), Freedom of Expression and Categories of Expression. In: SCANLON, T. M. (2003) The Difficulty of Tolerance: Essays in Political Philosophy. Cambridge: Cambridge University Press.

SCANLON, Thomas (2003b), A Theory of Freedom of Expression. In: SCANLON, T.M. (2003) The Difficulty of Tolerance: Essays in Political Philosophy. Cambridge: Cambridge University Press.

SCANLON, Thomas (2003c), The Difficulty of Tolerance. In: SCANLON, T.M. (2003), The Difficulty of Tolerance: Essays in Political Philosophy. Cambridge: Cambridge University Press.

SILVA, J. C. C. B. (2009), Democracia e Liberdade de Expressão: contribuições para uma interpretação política da liberdade de palavra. PhD Dissertation, Political Science Department, University of São Paulo.

SUNSTEIN, Cass (1995), Democracy and the Problem of Free Speech. New York: The Free Press.

TOCQUEVILLE, Alexis de. Democracy In America. New York: Library of America, Distr. By Penguin Putnam, 2004.

YOUNG, Iris M. (2010), Inclusion and Democracy. New York: Oxford University Press. 